\title{
Policy Acceptance of Low-Consumption Governance Approaches: The Effect of Social Norms and Hypocrisy
}

\author{
Dan Thorman *, Lorraine Whitmarsh and Christina Demski \\ School of Psychology, Tower Building, Cardiff University, Cardiff, CF10 3AS, UK; \\ whitmarshle@cardiff.ac.uk (L.W.); demskicc@cardiff.ac.uk (C.D.) \\ * Correspondence: ThormanD@cardiff.ac.uk
}

\begin{abstract}
Tackling over-consumption of resources and associated emissions at the lifestyle level will be crucial to climate change mitigation. Understanding the public acceptability of policy aimed at behaviour change in this domain will help to focus strategy towards effective and targeted solutions. Across two studies $(n=259,300)$ we consider how policy approaches at different levels of governance (individual, community, and national) might be influenced by the inducement of hypocrisy and the activation of social norms. We also examine the influence of these experimental manipulations upon behavioural intention to reduce consumption (e.g., repair not replace, avoiding luxuries). Dynamic social norm framing was unsuccessful in producing an effect on policy acceptance or intentions to reduce consumption. Information provision about the impact of individual consumption on global climate change increased support for radical policies at the national level (banning environmentally harmful consumption practices) and the community level (working fewer hours, sharing material products, collaborative food cultivation), yet the inducement of hypocrisy had no additional effect. This is in contrast to individual-level behavioural intentions, where the inducement of hypocrisy decreased intentions to engage in high-consumption behaviour. This paper concludes with implications for low-consumption governance.
\end{abstract}

Keywords: psychology; consumption; pro-environmental behaviour; policy acceptance; hypocrisy; social norms; neoliberalism; regulation; governance

\section{Introduction}

The world is experiencing drastic changes in its climate system, with the scientific community in agreement on the severity of climate change risks [1] and the need to avoid these risks for human societies and ecosystems [2]. The Paris Agreement has set targets to limit global warming to $1.5^{\circ} \mathrm{C}$ requiring aggressive emissions reductions. If we continue on the current trajectory and exceed $3{ }^{\circ} \mathrm{C}$ of warming, the results are likely to be catastrophic [3]. In order to limit warming to $1.5^{\circ} \mathrm{C}$, future scenario pathways show that new technology and increased energy efficiency will not be sufficient, and significant lifestyle changes are required [4]. One-quarter of global emissions are linked to the consumption and production of material products such as clothing, vehicles, electronics and household items [5] and we will need to reduce our consumption of these material goods in order to help tackle this problem effectively as part of an emissions reduction strategy. At the same time, other environmental and social impacts of material production, processing and consumption are profound and increasing [6]. Mining and material production generate pollution, threaten ecosystems, and deplete scarce natural resources [7], whilst extraction of metals finance armed conflicts and employ child labour [8]. Waste is also a growing concern, with the traditional waste management solution in many countries (including 
the UK) being landfilling, which is associated with various economic, health and environmental problems [9]. The UK produces nearly 27 million tons of household waste per year with only $40 \%$ being recycled [10]. The most effective way of reducing waste and mitigating the upstream problems associated with material extraction and production is to avoid consumption in the first instance [6]. Without direct policy initiatives from the UK government to tackle over-consumption beyond waste management and technologically driven efficiency gains, there is an increasing likelihood that our consumption levels, and associated emissions (and other social impacts), are going to continue to grow.

Some policy research has diagnosed climate change and associated sustainability problems (e.g., resource depletion) as global problems that require international commitments and collaboration [11-14], where global agreement could result in top-down regulation and target setting to cut emissions. This approach poses a huge challenge if there is not total cross-country agreement, prompting other researchers to advocate more devolved solutions [15-17], with a stronger focus on action at the sub-state level, including at community and household levels $[18,19]$. Therefore, there is a need to assess public acceptability of different consumption policies and associated lifestyle changes. This paper explores policy approaches that exemplify governance strategies at individual, community, and national levels.

Environmental behaviour change programmes have tended to lean towards a light-handed approach, with the responsibility to act appropriately being placed upon the individual. This represents a type of 'personal governance' where rational economic decision making is the assumed dominant mechanism behind behaviour. This is where consumers are given information and make informed decisions on what they want to support with their consumption choices, creating demand levels for a given market and preserving 'consumer sovereignty' [20]. Ideologically, and theoretically, a society operating a liberalised free market economy should self-regulate its moral and ethical compass, through this process where autonomous agents (consumers) act with no discrepancy between their action and belief [21]. In short, if a product or service was bad for society, individuals would not want it (there would be no demand), and therefore business would not provide it (there would be no supply). Preliminary research found this not to be the case and illustrated how people feel trapped into consuming in ways they do not necessarily condone yet are seen to be creating demand for the market to increase supply $[22,23]$. If people are unable to act in accordance to their morals, beliefs and values, we must question the mechanisms of economic decision making at the level of personal governance upon which markets are based.

This can be contrasted with 'national governance' approaches to policy change which involve more top-down regulation and increased control on the production of goods available for consumption. With this more goal-orientated approach to policy, targets can be decided and regulated for, increasing the likelihood of widespread behaviour change. Some of this regulation has been the result of shifts in public opinion and pressure on government to act [24]. A third form of governance can also be identified, 'community governance,' which seeks to address calls from Folke et al., who highlight a need to understand grassroots and local-level initiatives that could help pave the way to transformative change [25]. Climate policy has surpassed its usual goal of maintaining 'system resilience' and an exploration of radical change is required in order to make changes that are commensurate with the challenges posed by the climate crisis [25].

These varying policy approaches draw upon both conventional policy instruments like regulation, taxation and budgeting, and as well as instruments from literature on post-growth and sufficiency that seeks to reorient our economies and lifestyles around socio-ecological prosperity rather than economic growth and consumption. The approaches we categorise and propose here exemplify different strategies that could be used to inform policy and government strategy. They are not necessarily mutually exclusive, but it is useful to ascertain the support for them as distinct approaches to low consumption. This is to say that a combination of policy approaches might well be appropriate (especially across behavioural domains), but an understanding of public support for distinct elements is important to develop socially robust policies. 
Understanding public acceptability of these different governance approaches can help policy makers build support from their electorate, and give the political mandate required to make changes to individual lifestyles [26]. More generally, incorporating public perspectives into policy making is important for normative, substantive and instrumental reasons [27]. That is, in democratic societies, it is important to consult those who would be impacted by policies. Also, by consulting the public, we can improve the quality of policy outcomes by broadening the range of insights; and, finally, engaging the public can reduce opposition and build support for policies [27]. These rationales for public participation are particularly important when considering transformational policies with broad societal implications across multiple scales (including for lifestyles). Ascertaining the most attractive and democratically viable policy solutions to tackle over-consumption necessitates a psychological study into individual level decision-making regarding consumption practices.

From the environmental psychology literature, we know that social norms and hypocrisy have been found to encourage the uptake of some pro-environmental behaviours (PEB) such as recycling, plastic bag use, water conservation, etc. (see [28,29] for meta-reviews on social norms; [30] for hypocrisy). However, these approaches have not been applied to material consumption choices or to policy preferences in relation to reduced consumption; hence, the current research represents a much-needed advance towards redirecting environmental psychology towards high-impact pro-environmental behaviours [31]. This paper thus aims to explore the framing effects of social norms and hypocrisy inducement upon support for low-consumption policies representing different levels of governance, and a number of behaviours representing low-consumption lifestyle choices.

\subsection{Hypocrisy}

Hypocrisy studies are grounded in cognitive dissonance theory [32], which describes the mental state of holding two or more contradictory beliefs or values. Whereas cognitive dissonance often concerns attitudes, beliefs and values that are inconsistent with each other, hypocrisy is specifically concerned with attitudes, beliefs or values that are inconsistent with behaviour. The result of this inconsistency presents a threat to self-identity and self-integrity. Hypocrisy research has further explored how incoherence in one's self-identity and one's self-integrity often results in negative affect $[33,34]$. Being made aware of an inconsistency between one's values and one's action, i.e. hypocrisy, means the individual must either accept this inconsistency (along with any potential negative affect), or change their attitudes or behaviour in order to maintain more consistency in the future (and thus alleviate negative affect).

Previous research has utilized a hypocrisy paradigm in order to induce hypocrisy in participants, resulting in increased uptake of pro-environmental, ethical, and pro-social behaviours [30-35]. The hypocrisy paradigm was pioneered by Aronson, Fried and Stone [36] who designed an experiment that has since reliably induced hypocrisy and dissonance. Firstly, participants must advocate a pro-social (or pro-environmental) behaviour. Secondly, participants are asked to recall any past transgressions, the function of which is to increase the salience of any inconsistencies between past behaviour and the stance they have just advocated for. In previous experiments, the first stage of hypocrisy inducement has taken various forms, including signing petitions, posters or flyers [37-40], writing a list of reasons or a paragraph to promote the target behaviour [41-43], or being filmed giving a speech in support of a behaviour [33,36,41,44-48]. Research has shown that alterations in the commitment stage can lead to different behavioural responses. Specifically, behaviour change is more likely where the advocacy is a public display of support, rather than a private disclosure of advocacy. This public commitment more reliably produces hypocrisy and subsequent effects on behaviour change and/or intentions [49-51].

The second step, transgression recall, is less variable, and prompts the participant towards listing or rating the frequency of past behaviour. This serves to raise the awareness of a failure to adhere to one's own principles and is understood to increase the salience of hypocrisy in the respondent. This hypocrisy is unpleasant to the individual experiencing it, motivating them to reduce any associated 
psychological discomfort [36,49,52]; therefore, in the current experiment, we expect induced hypocrisy about high-consumption to increase intentions to engage in low-consumption behaviours.

This current research aims to increase the salience of hypocrisy and measure the impact it has on individual decision making, specifically on policy support and behavioural intentions. Due to a lack of research on hypocrisy and policy support, our hypothesis will be more exploratory. If participants are made to feel hypocritical, they are being confronted by the inconsistency between what they want to do, and what they do. We predict higher support for policy measures that involve regulation and control and lower support for policy that rely upon individual freedom and decision making. The hypocrisy is a result of their inability to match their autonomous decision making with their ideal course of action, and therefore there may be less willingness to be totally responsible for those decisions.

\subsection{Social Norms}

Social norms have been explored with relevance to pro-environmental behaviour (PEB) $[27,28]$, but not with specific relevance to reduced consumption lifestyles and acceptance of policy. This research contributes to this gap in the literature. Social norms have long been the subject of psychological enquiry, and more recent decades have yielded much research on their effect upon PEBs, most of which are rooted in theory of normative conduct [53], pioneered by Cialdini and colleagues [27].

A meta-review of social norms and PEB has shown that descriptive norms are more effective than injunctive norms in eliciting behaviour change [28]. Descriptive norms illustrate what most people actually do, whereas injunctive norms illustrate what most people should or ought to do. Descriptive norms around low consumption are unlikely to be evident in today's consumerist society, which presents problems about how this experimental manipulation might be received plausibly by participants. Additionally, research has found hypocrisy studies to be most effective when the norms are well accepted [49-54]. Relevant to this concern is the more recent research into dynamic social norms, which have been influential on emergent and less well-established norms $[55,56]$. This manipulation presents a social norm that is emergent, illustrating that there is an uptake of the target behaviour or belief and that it is becoming a social norm. This specific type of norms framing has been effective for promoting water consumption in the home [55].

Social norms that are framed around relevant social groups are found to be more effective in provoking take-up of a behaviour, as opposed to framing a social norm around a group that one might feel little affiliation and identification with $[57,58]$. This study will emphasise a UK-specific dynamic descriptive norm in order to ensure that all respondents (recruited from the UK) are within a relevant social group. By framing the uptake of the desirable behaviour rather than drawing attention to transgressions of non-adopters we avoid inadvertently portraying high-consumption lifestyles as normative. Social norms have been found to be most effective when they activate guilt within participants [59]. If the respondents in the social norm condition are aware that others in their community (in this case, other UK citizens) are reducing their environmental impact, they could be motivated to make commitments to low-consumption behaviours out of anticipated guilt or shame [60]. Therefore, activating social norms in conjunction with inducing hypocrisy is likely to produce an interaction effect whereby social norms have a larger effect on decreasing consumption when hypocrisy has been induced.

It will be beneficial to consider how social norms can influence the public acceptance of policy measures, and whether or not they might affect the support for more radical social transformation that is being called upon to address climate breakdown. There is contradictory evidence around the interaction of social norms and public policy, with some studies supporting the notion that public policy change can bring about social norms [61,62], and others vice versa, that social norms around an issue can provoke the creation of public policy [24]. The latter is more in line with the research on PEB. Understanding this relationship better, by ascertaining effects of social norms upon policy acceptance and behavioural intention, can help inform effective policy making. 


\section{Study 1}

\subsection{Hypotheses}

Study 1 experimentally examined how different manipulations of social norms and hypocrisy inducement can influence intentions for individual level behaviour change and acceptability of public policy at different levels of governance. Based on previous research, our hypotheses are:

Hypothesis 1 (H1). The social norm framing will result in an increase in low-consumption behavioural intentions and increase support for national governance of radical and transformative policy measures (regulation from government level, consumption budgets, local community sharing economy) and decrease support for policies that operate at a level of personal governance (environmental taxation, deregulating markets).

Hypothesis 2 (H2). The hypocrisy manipulation will decrease consumption behavioural intentions and increase support for national governance of radical and transformative policy measures (regulation from government level, consumption budgets, local community sharing economy) and decrease support for policies that operate at a level of personal governance (environmental taxation, deregulating markets).

Hypothesis 3 (H3). An interaction effect will occur where the social norm framing will increase the influence of the hypocrisy framing.

\subsection{Method}

\subsubsection{Design}

The current study employed a $2 \times 3$ between-participants experimental survey design that operationalised two independent variables: social norm framing (control, social norms) and induced hypocrisy (control, advocacy, and hypocrisy) (See Table 1). The effect of these conditions was measured against the two sets of dependent variables: acceptability of policies to support low-consumption lifestyles, and behavioural intentions to reduce one's own consumption.

Table 1. The $2 \times 3$ experimental design with numbered condition groups.

\begin{tabular}{cccc}
\hline & Control & Advocacy & Hypocrisy \\
\hline Control & 1 & 3 & 5 \\
Social Norms & 2 & 4 & 6 \\
\hline
\end{tabular}

\subsubsection{Participants}

The study recruited 259 participants from the UK using an online participant panel (Prolific) (see Appendix B for exclusion criteria information). Participants were randomly assigned to one of the six conditions via a randomizer function in Qualtrics (See Table 2 for demographic information of participants per condition). More participants were in the lower income brackets (average [median] wage in the UK is $\sim £ 28,000$, with results showing that the sample is skewed towards the lower incomes, which is typical for most research), and more participants self-identified as being left-wing, than right-wing. A Chi-squared distribution test showed that age, income and political affiliation were non-significantly different across the conditions; however, gender was significantly unbalanced across conditions. Income and political orientation were not correlated $(r=0.05, p=0.42)$ and a one-way ANOVA showed that political orientation was not predicted by income $\left(F_{4,254}=1.17, p=0.32\right)$. 
Table 2. Socio-demographic characteristics of participants, by condition (study 1).

\begin{tabular}{|c|c|c|c|c|c|c|c|}
\hline & $\begin{array}{c}\text { All (n, } \\
\text { 259) }\end{array}$ & $\begin{array}{l}\text { 1. Control } \\
(n, 58)\end{array}$ & $\begin{array}{c}\text { 2. Control } \\
\text { w/Social } \\
\text { Norms }(n, 43)\end{array}$ & $\begin{array}{c}3 . \\
\text { Advocacy } \\
(n, 40)\end{array}$ & $\begin{array}{l}\text { 4. Advocacy } \\
\text { w/Social } \\
\text { Norms }(n, 37)\end{array}$ & $\begin{array}{c}5 . \\
\text { Hypocrisy } \\
(n, 39)\end{array}$ & $\begin{array}{l}\text { 6. Hypocrisy } \\
\text { w/Social } \\
\text { Norms }(n, 42)\end{array}$ \\
\hline \multicolumn{8}{|l|}{ Age } \\
\hline $25-34(\%)$ & 35.9 & 36.2 & 39.5 & 35.0 & 32.4 & 33.3 & 38.1 \\
\hline $35-44(\%)$ & 17.8 & 19.0 & 23.3 & 20.0 & 8.1 & 17.9 & 16.7 \\
\hline $45-54(\%)$ & 15.8 & 17.2 & 14.0 & 12.5 & 21.6 & 12.8 & 16.7 \\
\hline \multicolumn{8}{|l|}{ Gender } \\
\hline Male (\%) & 48.6 & 56.9 & 67.4 & 42.5 & 35.1 & 33.3 & 50 \\
\hline Female (\%) & 51.4 & 43.1 & 32.6 & 57.5 & 64.9 & 66.7 & 50 \\
\hline \multicolumn{8}{|l|}{ Income } \\
\hline Up to $£ 15,599$ (\%) & 39.4 & 36.2 & 39.5 & 35.0 & 35.1 & 51.3 & 40.5 \\
\hline$£ 36,400$ and above $(\%)$ & 11.2 & 8.6 & 16.3 & 15.0 & 13.5 & 10.3 & 4.8 \\
\hline Prefer not to say $(\%)$ & 5.8 & 6.9 & 4.7 & 7.5 & 10.8 & 0 & 4.8 \\
\hline \multicolumn{8}{|l|}{ Political Orientation } \\
\hline $\begin{array}{l}\text { Politics score }(0=\text { extreme } \\
\text { left, } 10=\text { extreme right })\end{array}$ & 4.12 & 3.86 & 4.40 & 4.18 & 3.97 & 3.90 & 4.45 \\
\hline Left-wing $(0-3)(\%)$ & 39.4 & 48.3 & 32.6 & 35.0 & 43.2 & 35.9 & 38.1 \\
\hline Centre (4-6) $(\%)$ & 48.0 & 39.6 & 35.8 & 60.0 & 40.6 & 43.8 & 47.6 \\
\hline Right-wing (7-10) (\%) & 12.6 & 12.1 & 11.6 & 5.0 & 16.2 & 10.3 & 14.3 \\
\hline
\end{tabular}

\subsubsection{Materials}

All materials used in this research were accessed by participants using Qualtrics, an online digital survey distribution software package. Analysis for descriptive and inferential statistics was conducted using IBM SPSS statistical analysis software (ver. 25).

\subsubsection{Procedure}

All participants first read information about the study and data protection and were required to give informed consent. Participants were then given factual information about climate change and consumption, in order to give reference to why policy support and behaviour change might be required (see Appendix A). Experimental manipulation of social norms was implemented through the provision of a graph and short statement (Figure 1. detailed below in Section 2.2.5), which was added to the end of the information statement. Experimental manipulation of hypocrisy was carried out in accordance with the established practice detailed in Sections 1.1 and 2.2.6 where participants in the advocacy and hypocrisy conditions were asked to sign a pledge in order to state their advocacy for a given course of action, in this case to reduce their consumption. Following this, participants in the hypocrisy condition were then immediately asked to recall times in the recent past when their behaviour has transgressed from this pledged advocacy. After these various manipulations, all participants completed the dependent variable items on policy support and behavioural intentions. Finally, a dissonance thermometer was used to measure hypocrisy in each group as a manipulation check (see Section 2.3.1). After the survey, participants were debriefed, including explaining the social norms deception. 


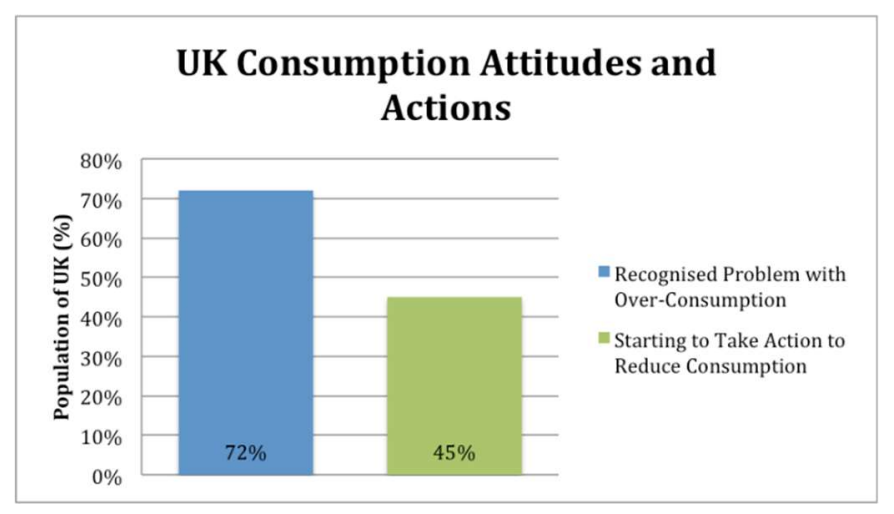

Figure 1. Dynamic social norms framing chart.

\subsubsection{Social Norms Framing}

The first stage of the experimental design constituted an information statement with a number of facts about consumption and climate change. This stage of the design had two conditions, one condition included only this information statement, the second included a social norms statement with a descriptive norm about how many people recognise over-consumption as a problem, followed by a dynamic descriptive norm that details a percentage of these who recognise the problem and are starting to take actions to reduce consumption. The statement read as follows: "A recent survey found that the majority ( $72 \%)$ of people in the U.K. realise our consumption levels are too high, and of those people, $45 \%$ are already taking steps to live more sustainably by buying less."

The figures used in the social norm manipulation were not factual and had been developed in order to present low consumption as a social norm. This method of deception is common in research and participants were subsequently debriefed.

\subsubsection{Hypocrisy}

The second part of the experiment was the hypocrisy manipulation, which consisted of three levels. The first being a control group with no experimental manipulation. In the other two levels participants were asked to sign a pledge and make a commitment to reduce their own consumption (see Figure 2). Participants were told that their signature would be publicly displayed. While in actual fact their signatures were never publicly displayed, it was important the participants believed that the advocacy pledge would be public as this is the most effective at eliciting behaviour change [30].

In the hypocrisy condition, participants were also asked to sign the pledge (as in the advocacy condition) but were then also asked to rate the frequency of any behavioural transgressions that contradict their pledge to reduce consumption. This had the aim of making participants aware of their own lack of consistency in their behaviour with the pledged advocacy regarding consumption. Participants were asked "how many times in the past week have you bought ...?" in relation to four items; 'an item made of (or packaged with) single use plastic', 'a product that is not ethically produced', 'food that you have ended up throwing away', and 'something that you didn't really need' (rated 1-6: 'not at all' (1), 'once' (2), 'a few times' (3), 'often' (4), 'every day' (5), and 'more than once a day' (6) - an additional option of 'don't know' was excluded from analyses). Participants were also asked "how many times in the past year have you bought ... ?" in relation to two items; 'a new replacement product, instead of repairing an old one' and 'an expensive luxury item' (rated 1-6: 'not at all' (1), 'once' (2), 'a few times' (3), 'often' (4), 'every day' (5), and 'more than once a day' (6), with an additional option of 'don't know' which was excluded from analyses). 
As part of this project we are creating a petition for you to sign. This is a way for you to show your support, and encourage members of the public and government policy makers to reduce consumption levels.

This petition will be published online and sent to your local MP. Should you wish to, you can share this petition on your social media, links will be provided at the end of the study. This is not linked to your other answers in this survey, and will not be stored by prolific.

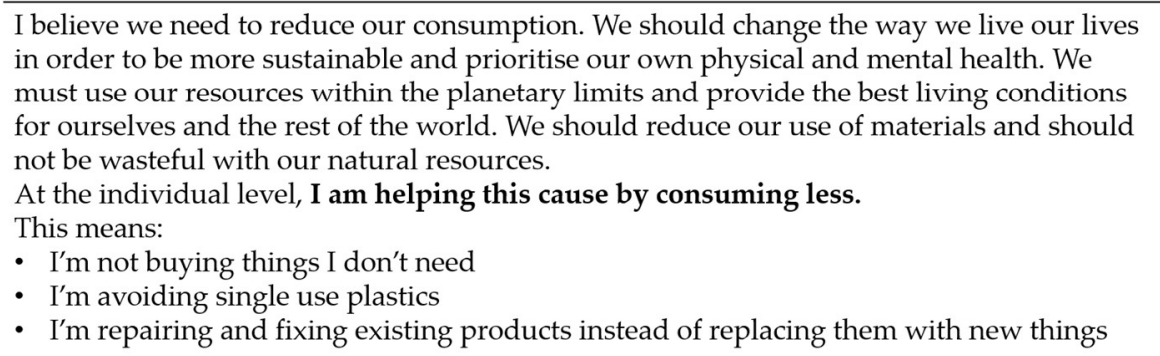

Please add your name in the box below to show your public support for this claim.

Figure 2. Advocacy statement for hypocrisy conditions 2 and 3.

\subsection{Measures}

\subsubsection{Hypocrisy Manipulation Check}

A 'dissonance thermometer' was used in order to measure cognitive dissonance, a scale that was developed by Eliot and Devine [34]. This has been used in some previous research as a proxy for measuring hypocrisy. This measure was reduced to an eight-item scale representing the four dimensions of dissonance: negative self-directed affects ('disappointed in myself' and 'disgusted in myself'), psychological discomfort ('uncomfortable' and 'bothered'), anxiety ('stressed' and 'worried'), and positive affects ('content' and 'happy'). A ninth item was added to try and assess self-reported feelings of hypocrisy; this was labelled 'hypocritical'. Correlations between the dissonance thermometer and the hypocrisy item help gauge the effectiveness of the scale. All items were answered in response to the question "at the moment, to what extent do you feel ...?" (1-7, with a label at each end of the scale 'does not correspond to how I feel' (1) and 'completely corresponds with how I feel' (7)) as per the procedure of Pelt et al. (2018).

The dissonance thermometer showed very strong reliability using Cronbach's Alpha score for scale reliability testing $(\alpha=0.91)$ and correlated significantly with the additional hypocrisy item $(r=0.53$, $p<0.01)$. However, when a one-way ANOVA was conducted on the sample, no significant difference was found in the dissonance of the participants across the conditions, when using the dissonance thermometer $\left(F_{2,259}=1.01, p=0.36\right)$. Nor was there a significant difference between the hypocrisy conditions when using the 'hypocrisy' item $\left(F_{2,259}=0.584, p=0.558\right)$.

In order to try and make further sense of this result, we can look at the subsection of participants who completed the transgression scores and see if the degree to which a participant transgressed in their consumption behaviour led to a more hypocritical rating. Transgression scores were positively correlated to higher self-reported hypocrisy specific item score $(r=0.22, p=0.024)$ and marginal significance with the dissonance thermometer $(r=0.181, p=0.053)$.

\subsubsection{Dependent Variables}

The dependent variables were behavioural intentions and policy support items. The items used for the transgressions were included when asking about behavioural intentions along with two additional PEB items ('Travel by foot, bike, bus or train instead of by car or plane' and 'Choose to eat vegetarian/vegan meals and cut down on meat'; both of these items were reverse coded for analysis). Participants were asked 'Think about the next month, and your intentions regarding the following 
actions. How often will you?' with a five item scale (rated 1-5, 'not at all' (1), 'once' (2), 'a few times' (3), 'often' (4), 'always' (5), and a further option, 'don't know' which was excluded from analysis).

The policy support items were measured on a six-item scale (rated 1-7, 'completely oppose' (1), 'strongly oppose' (2), 'slightly oppose' (3), 'neither oppose nor support' (4), 'slightly support' (5), 'strongly support' (6), and 'completely support' (7)). The six items represented the following policies:

- Consumption budget: "Government policy should introduce an individual consumption budget where calculations are made around the impact of the things you buy and you are individually responsible for your consumption footprint. You would have a limit to how much, and what you can buy."

- Environmental taxation: "Government should introduce a tax on activities and products that are damaging to the environment or people. This would make it more expensive to produce and buy products that are environmentally or socially damaging but they would still be available."

- Regulation to ban products: "Government policy should regulate businesses to produce and sell only sustainable and ethical products. For example, cheaply produced clothes and electronics will be banned"

- Reduce working hours: "There should be a reduction in working hours. This would mean we have more time to spend with family, and actively engaging in more activities (making things and growing food etc.). This would also mean we have less money to spend, and we wouldn't be able to buy as many things."

- Free-market deregulation: "Business should be given more freedom from government to meet demand. Products would only become more environmentally-friendly if people chose greener products. This 'deregulation' doesn't guarantee a reduction in consumption."

- Community sharing/fixing economy: "Local community groups should have support from the government to set up 'repair cafes' and 'library of things' so we can be better equipped to fix things we have, and share appliances and products we don't need to own. This would be cheaper but less convenient than owning them ourselves."

\subsection{Results}

\subsubsection{Policy Measure Support}

A multivariate analysis of variance (MANOVA) was conducted (using Pillai's trace), finding a non-significant effect of social norms on policy acceptance measures, $V=0.022, F_{6}, 248=0.920, p=0.48$ and a non-significant effect of hypocrisy inducement on policy acceptance measures, $V=0.071, F_{12,498}$ $=1.53, p=0.11$, as well as non-significant interaction effects of social norms and hypocrisy inducement on policy acceptance measures, $V=0.043, F_{12,498}=0.914, p=0.53$. However, there were marginally significant results with separate univariate between-subjects tests illustrating effects of hypocrisy inducement on the regulation of markets, $F_{2,253}=2.38, p=0.095$ (Figure 3), and on the deregulation of markets, $F_{2,253}=2.74, p=0.067$ (Figure 4). Hypocrisy marginally reduced willingness to support government regulation, and increased support for deregulation and free-market business solutions. Table 3 shows overall means and sub-group condition means for policy support. 


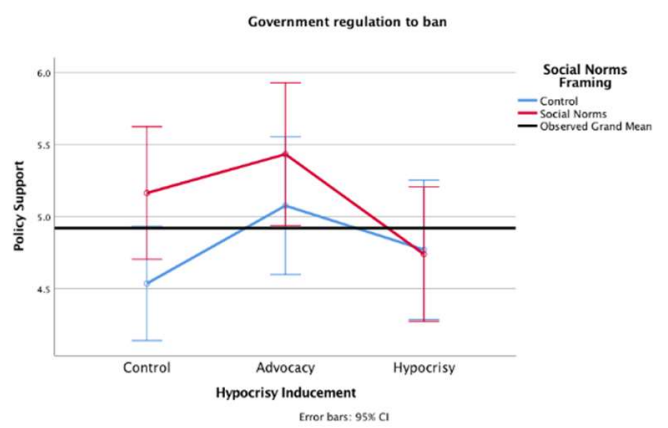

Figure 3. Experimental conditions and support for increased regulation.

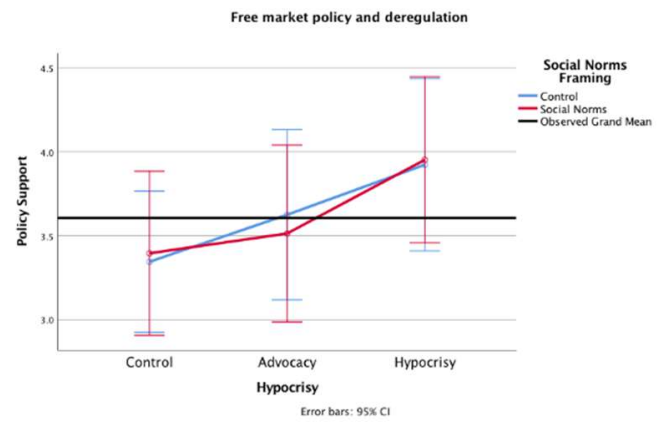

Figure 4. Experimental conditions and support for free-market policy and deregulation.

Table 3. Overall means (and standard deviations) showing support for policy measures.

\begin{tabular}{|c|c|c|c|c|c|c|c|}
\hline & $\begin{array}{c}\text { All [n, } \\
\text { 259] (S.D.) }\end{array}$ & $\begin{array}{l}\text { 1. Control } \\
\text { [n, 58] } \\
\text { (S.D.) }\end{array}$ & $\begin{array}{l}\text { 2. Control } \\
\text { w/Social } \\
\text { Norms [n, } \\
\text { 43] (S.D.) }\end{array}$ & $\begin{array}{c}3 . \\
\text { Advocacy } \\
{[n, 40]} \\
\text { (S.D.) }\end{array}$ & $\begin{array}{c}4 . \\
\text { Advocacy } \\
\text { w/Social } \\
\text { Norms [n, } \\
\text { 37] (S.D.) }\end{array}$ & $\begin{array}{c}5 . \\
\text { Hypocrisy } \\
{[n, 39]} \\
\text { (S.D.) }\end{array}$ & $\begin{array}{c}6 . \\
\text { Hypocrisy } \\
\text { w/Social } \\
\text { Norms [n, } \\
\text { 42] (S.D.) }\end{array}$ \\
\hline \multicolumn{8}{|l|}{ Policy } \\
\hline $\begin{array}{c}\text { Community } \\
\text { sharing/Fixing economy }\end{array}$ & $5.75(1.19)$ & $5.60(1.43)$ & $5.59(0.94)$ & $5.80(1.14)$ & $5.69(1.26)$ & $5.82(1.08)$ & $5.53(1.32)$ \\
\hline Environmental tax & $5.07(1.49)$ & $5.12(1.50)$ & $5.20(1.45)$ & $4.94(1.74)$ & $4.81(1.67)$ & $4.96(1.55)$ & $4.81(1.53)$ \\
\hline Government regulation to ban & $4.92(1.55)$ & $4.53(1.59)$ & $5.12(1.51)$ & $4.72(1.72)$ & $5.26(1.64)$ & $4.68(1.79)$ & $4.47(1.54)$ \\
\hline Reduce working hours & $4.61(1.69)$ & $4.22(1.86)$ & $4.78(1.75)$ & $4.74(1.65)$ & $4.67(1.60)$ & $4.34(1.73)$ & $4.42(1.76)$ \\
\hline Consumption budget & $3.94(1.71)$ & $3.81(1.85)$ & $3.78(1.49)$ & $4.06(1.81)$ & $3.89(1.86)$ & $3.70(1.71)$ & $3.65(1.81)$ \\
\hline $\begin{array}{c}\text { Free market policy and } \\
\text { deregulation }\end{array}$ & $3.61(1.63)$ & $3.34(1.63)$ & $3.47(1.65)$ & $3.63(1.61)$ & $3.48(1.69)$ & $3.76(1.64)$ & $3.86(1.48)$ \\
\hline
\end{tabular}

\subsubsection{Behavioural Intentions}

A MANOVA was conducted (using Pillai's trace), finding a non-significant effect of social norms on behavioural intentions, $V=0.126, F_{8,32}=0.57, p=0.79$ and a significant effect of hypocrisy inducement on behavioural intentions, $V=0.664, F_{16,66}=2.05, p=0.02$, as well as non-significant interaction effects of social norms and hypocrisy inducement on behavioural intentions, $V=0.482, F_{16,66}=1.31, p=0.22$. Table 4 shows overall means and sub-group condition means for behavioural intentions.

There were also significant results with between-subject effects illustrating effects of hypocrisy inducement on behavioural intentions related to ethical purchasing $\left(F_{2,126}=6.95, p<0.005\right)$ and replacing and repairing $\left(F_{2,166}=4.78, p=0.014\right)$. Ethical purchasing showed significant differences between the hypocrisy control group and advocacy only group with Bonferroni corrected post-hoc testing ( $p=0.012$ ) showing the advocacy only group had lower intentions to engage in purchasing unethical products than the control group. There were also between-subject interaction effects of social norms and hypocrisy inducement on replacing and repairing $(F(2,126)=3.53, p=0.039)$ showing that when social norms were present the advocacy only group had lower intentions to engage in over-consumption and the hypocrisy group had higher intentions to over-consume. See Figures 5 and 6 below for reference of this. 
Table 4. Overall means (and standard deviations) for intention to engage in consumption behaviours.

\begin{tabular}{|c|c|c|c|c|c|c|c|}
\hline & $\begin{array}{l}\text { All (n, } \\
259)\end{array}$ & $\begin{array}{l}\text { 1. Control } \\
(n, 58)\end{array}$ & $\begin{array}{l}\text { 2. Control } \\
\text { w/Social } \\
\text { Norms }(n, 43)\end{array}$ & $\begin{array}{l}\text { 3. Advocacy } \\
(n, 40)\end{array}$ & $\begin{array}{l}\text { 4. Advocacy } \\
\text { w/Social } \\
\text { Norms }(n, 37)\end{array}$ & $\begin{array}{l}\text { 5. Hypocrisy } \\
(n, 39)\end{array}$ & $\begin{array}{l}\text { 6. Hypocrisy } \\
\text { w/Social } \\
\text { Norms }(n, 42)\end{array}$ \\
\hline \multicolumn{8}{|l|}{ Behavioural intention item } \\
\hline Buy new instead of repair & $3.14(1.49)$ & $2.84(1.46)$ & $3.33(1.36)$ & $2.68(1.29)$ & $3.16(1.57)$ & $3.42(1.57)$ & $3.47(1.45)$ \\
\hline Use single-use plastic & $3.02(1.01)$ & $3.10(0.88)$ & $3.37(0.79)$ & $3.19(0.76)$ & $2.86(1.10)$ & $2.96(1.12)$ & $2.77(1.08)$ \\
\hline Buy unethical products & $2.47(1.14)$ & $2.58(1.15)$ & $3.21(1.28)$ & $2.42(1.09)$ & $2.63(1.39)$ & $2.10(1.07)$ & $2.52(1.12)$ \\
\hline $\begin{array}{c}\text { Make an } \\
\text { unnecessary Purchase }\end{array}$ & $1.9(.95)$ & $2.00(0.94)$ & $2.02(0.81)$ & $1.88(1.02)$ & $1.94(0.98)$ & $1.90(0.90)$ & $1.87(1.06)$ \\
\hline Waste food & $1.68(.94)$ & $1.67(0.91)$ & $1.94(0.99)$ & $1.85(1.00)$ & $1.93(1.13)$ & $1.53(0.89)$ & $1.47(0.94)$ \\
\hline Buy a luxury item & $1.37(.69)$ & $1.40(0.84)$ & $1.32(0.63)$ & $1.44(0.79)$ & $1.54(0.87)$ & $1.24(0.48)$ & $1.33(0.61)$ \\
\hline
\end{tabular}

${ }^{1}$ Actual item was "how often will you choose to eat vegetarian/vegan meals and cut down on meat" so the label and figures have been reversed to maintain harmony in the scale. ${ }^{2}$ Actual item was "how often will you to travel by foot, bike, bus or train instead of by car or plane" so the label and figures have been reversed to maintain harmony in the scale.

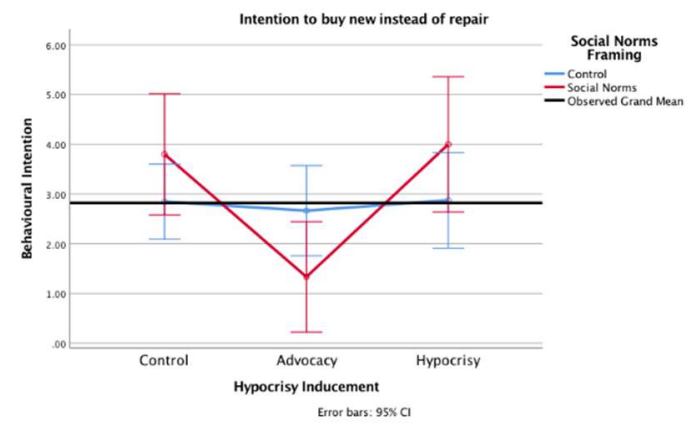

Figure 5. Experimental conditions and intentions to buy new instead of repair.

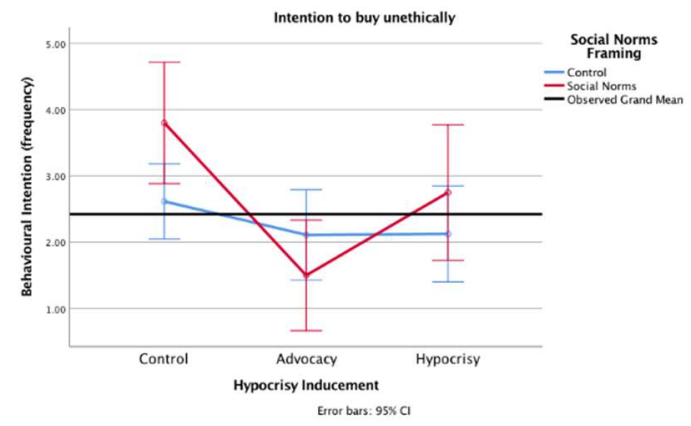

Figure 6. Experimental conditions and intentions to buy unethically sourced products.

\subsection{Discussion}

The social norms framing was not found to influence support for different policy measures, nor did they appear to influence people's intentions to consume less. In light of these results we must reject $H 1$. The inducement of hypocrisy did not influence support for policy and governance but did have an effect on behavioural intentions to reduce consumption. However, the results do not indicate that hypocrisy itself increases intention to lower one's consumption specifically, but the act of a commitment and advocacy to reduce consumption helps to reinforce this as a behavioural intention. These findings mean we must also reject $H 2$. $H 3$ can be partially retained due to a significant interaction effect illustrating that the effects of the hypocrisy manipulation were strengthened in the social norms condition when evaluating the behavioural intentions. No interaction effect was found between social norms and hypocrisy when evaluating the impact of the experiment on policy and governance support. 
The failings of a social norm manipulation could be interpreted in light of recent research from Richter, Thøgersen and Klöckner [63] who reliably replicated the appearance of a 'Boomerang' effect on the social norms manipulation in their study on sustainable consumption choices in the supermarket. This effect is when the target behaviour of the social norm manipulation results in the increased uptake of the behaviour that one is seeking to reduce. This effect was also found in other research $[64,65]$. Richter et al. [63] suggest that a descriptive norm of an undesirable behaviour that is particularly common can have a negative impact on attempts to reduce the target behaviour. The use of a dynamic descriptive norm in this study could have reproduced this, as it acknowledges that a given behaviour is currently widespread, despite suggesting that there is a strong movement towards people changing this behaviour. In hindsight, this manipulation may have legitimised hypocrisy by showing that there are people who are thinking about changing their consumption patterns, but not translating this into behaviour.

The dynamic social norm statistics reported to participants about how many people in the UK were reducing their consumption were not true. In fact, UK consumption figures showing steady growth of household final consumption expenditure [66]. Therefore, it is possible that participants did not truly feel like they would be following a social norm by adopting the low-consumption behaviours. The social norms manipulation check suggested that they were not sceptical of the information, and believed it to be truthful; however, there is a possibility that the norm of consumption is so strong it cannot be easily manipulated by a simple statistical graph. The reason for the lack of effect could also be the result of a failed activation of the dynamic descriptive social norm relevant to policy or governance. The norm activation was designed to make it salient that most people in the UK were beginning to take action in tackling their consumption levels, and lead people into conforming to this apparent norm. This did not specify a policy preference or support for a type of governance; therefore, there was no social norm activation for policy support, only for behaviour change relevant to it.

The hypocrisy framing showed a marginal effect of advocacy on behavioural intentions to repair existing products and purchase ethical goods. These two items both represent a strong commitment to a lifestyle change that is relatively time-intensive and effortful. We can infer from this that making a pledge and committing to reduce one's consumption behaviour resulted in a stronger desire to follow this up with direct action. However, if hypocrisy is induced after this commitment stage, then the effects are no different to receiving no message at all. This could be explained by research that has shown how increased salience of hypocrisy can also evoke a 'rebound' effect, where individuals harden their stance and refuse to change their habits. One reason for this might be that people find it easier to renege on their recent advocacy statement and change their beliefs to be in accordance with the transgression of the target behaviour, and find this a suitable way to relieve themselves from any negative affect arising from the arousal of dissonance $[30,40,67,68]$. We must understand the conditions of this rebound effect as it is important to understand when activating the salience of hypocrisy is useful or not [69].

The marginal significance of support on policy measures does hint towards the possibility that hypocrisy reduces support for national governance and regulation and increases support for personal governance through deregulation and free-market economy mechanisms. The finding suggests that hypocrisy is not a useful mechanism for increasing support for national governance and regulation. This brings into question how appropriate it is for our behaviour change programs to focus on individual responsibility and decision making. Because hypocrisy reinforces a sense of personal moral responsibility for one's actions, it could be perpetuating an individualistic approach. This could help make sense of why it empowers individuals to change their intentions and reduces their willingness to absolve themselves of this responsibility. However, this could benefit from further exploration in a future study.

Because the hypocrisy manipulation check showed no difference between conditions, there is a chance that the measure was not recording levels of hypocrisy prior to the chance participants had to ameliorate and relieve their negative affect. This could be achieved by supporting a policy they 
felt would solve the problem, or by reinforcing their intention to consume less. Additionally, all participants were given information about consumption that may have induced hypocrisy to those participants in the control group. A pure control experimental group and a revised placement of the hypocrisy measures manipulation check should be sought in future research. Another significant caveat that should be made in regards to the effects of hypocrisy upon intentions to reduce consumption behaviour is the smaller sample size of the two significant items. Due to a lot of participants selecting 'don't know' for some of the items, there is potentially a problem with a lack of power.

\subsection{Conclusions}

Inducing social norms was not effective in this study, which could be due to a weak manipulation or a boomerang effect. Additionally, making the public feel hypocritical did not increase their willingness to accept stronger regulation. Offering a commitment to advocate and pledge for a change in their behaviour, however, increased support for regulation and more transformative radical policy, and decreased intentions to live a high-consumption lifestyle.

\section{Study 2}

A replication study was devised to simplify and strengthen the research design. Alterations were made in order to create a more obvious distinction between the policy options and make them more relevant to different levels of governance and policy approaches. They will now more distinctly represent 'National Governance and Regulation', 'Personal governance with deregulation of free markets', and 'Local and community governance with radical change' (see Section 3.2.6 for new items). The social norms manipulation was removed, as this did not result in significant findings in Study 1. A pure control was introduced in order to establish the effects of providing relevant information versus no information. This would allow the study to ascertain how influential it was to give participants information about the effects of their consumption behaviours with reference to global climate change, and in turn, if the hypocrisy manipulation increased or decreased this effect. Finally, amendments were made to the behavioural intention items to provide examples about what the behaviour changes were (see Section 3.2.6).

\subsection{Hypotheses}

Hypothesis 4 (H4). Hypocrisy manipulation will increase support for national governance and radical policy measures and decrease support for policies that operate at a level of personal governance.

Hypothesis 5 (H5). Hypocrisy manipulation will decrease intentions to engage in consumption behaviours.

\subsection{Method}

\subsubsection{Participants}

The study recruited 300 participants from a UK sample, again using Prolific. Table 5 presents socio-demographic characteristics of the sample in study 2. A Chi-squared distribution test showed that age, gender, and political orientation were non-significantly different across the conditions; however, income was significantly unbalanced across conditions. Income and political orientation were not correlated $(r=0.09, p=0.13)$ and a one-way ANOVA showed that political orientation was not predicted by income $\left(\mathrm{F}_{4,295}=1.16, p=0.33\right)$. 
Table 5. Socio-demographic characteristics of participants, by condition (study 2).

\begin{tabular}{|c|c|c|c|c|c|}
\hline & All $(n, 300)$ & Control $(n, 77)$ & Information $(n, 75)$ & Advocacy $(\mathrm{n}, 73)$ & Hypocrisy $(\mathrm{n}, 75)$ \\
\hline \multicolumn{6}{|l|}{ Age } \\
\hline $18-25(\%)$ & 24 & 24.7 & 22.7 & 26 & 22.7 \\
\hline $25-34(\%)$ & 37.3 & 40.3 & 34.7 & 37 & 37.3 \\
\hline $35-44(\%)$ & 21 & 18.2 & 20 & 21.9 & 24 \\
\hline $45-54(\%)$ & 12.3 & 7.8 & 16 & 13.7 & 12 \\
\hline $55-64(\%)$ & 4 & 6.5 & 5.3 & 1.4 & 2.7 \\
\hline $65+(\%)$ & 1.3 & 2.6 & 1.3 & 0 & 1.3 \\
\hline \multicolumn{6}{|l|}{ Gender } \\
\hline Male (\%) & 23.3 & 20.8 & 30.7 & 19.2 & 22.7 \\
\hline Female $(\%)$ & 76.7 & 79.2 & 69.3 & 80.8 & 77.3 \\
\hline \multicolumn{6}{|l|}{ Income } \\
\hline Up to $£ 15,599$ (\%) & 34.7 & 39 & 37.3 & 35.6 & 26.7 \\
\hline $\begin{array}{c}\text { Between } £ 15,600 \text { and up to } \\
£ 25,999(\%)\end{array}$ & 31.7 & 26 & 24 & 28.8 & 48 \\
\hline $\begin{array}{c}\text { Between } £ 26,000 \text { and up to } \\
£ 36,399(\%)\end{array}$ & 19.3 & 22.1 & 22.7 & 17.8 & 14.7 \\
\hline$£ 36,400$ and above (\%) & 10.3 & 10.4 & 14.7 & 12.3 & 4 \\
\hline Prefer not to say (\%) & 4 & 2.6 & 1.3 & 5.5 & 6.7 \\
\hline \multicolumn{6}{|l|}{ Political Orientation } \\
\hline $\begin{array}{l}\text { Politics score }(0=\text { extreme left, } \\
10=\text { extreme right })\end{array}$ & 4.12 & 4.31 & 3.89 & 4.14 & 4.12 \\
\hline Left-wing (0-3) (\%) & 40 & 37.7 & 46.7 & 37 & 38.7 \\
\hline Centre (4-6) (\%) & 49.7 & 51.6 & 44 & 42.8 & 49.3 \\
\hline Right-wing (7-10) (\%) & 10.3 & 11.7 & 9.3 & 9.2 & 12 \\
\hline
\end{tabular}

\subsubsection{Design}

This study employed a $1 \times 4$ between-participants design. The four conditions were as follows:

1. A pure control group where participants were given no information,

2. An information only group where participants were provided with information on climate change and the role of consumption,

3. An advocacy only group in which participants were shown the information on climate change followed by a commitment to reduce their consumption behaviours, and

4. A hypocrisy group in which participants were provided with the information, asked to make a commitment to reduce their consumption behaviour followed by listing their recent transgressions with regards to consumption behaviours.

The dependent variables consisted of two sets: three low-consumption policy approach items, and six consumption behaviour intention items.

\subsubsection{Materials}

Materials were the same as in Study 1.

\subsubsection{Independent Variables}

The social norms framing was removed for this study, and the hypocrisy level was expanded to include four conditions. The information given was introduced as an experimental condition, and was the same information from the first study. Materials for the advocacy pledge were also kept the same. A slight change was made to the transgression list, in order to make it clearer how each behavioural domain was relevant to actual actions, e.g., "...something made of, or packaged with, single use plastic (e.g., plastic wrapped salad/vegetables, crisp packets, soft drinks bottles)", "...a new product instead of fixing an old one (e.g., repairable shoes, electronic devices)", and "...a product that is not ethically produced (e.g., made with cheap labour, conflict metals, damaging to the environment)". These items were all amended to have the same 'polarity', instead of having reversed items as in Study 1, in order to reduce cognitive load. 


\subsubsection{Hypocrisy Manipulation Check}

The dissonance thermometer was the same as in Study 1; however, it was moved to before the dependent variables. This was due to concerns in Study 1 that the placement of this measure at the end of the study meant that any negative affect or dissonance resulting from the hypocrisy had been ameliorated by support for policy and expressed intentions to consume less.

The dissonance thermometer $(\alpha=0.89$ ) was significant positively correlated with the hypocrisy item $(r=0.54, p<0.001)$. A one-way ANOVA showed that hypocrisy was significantly different across conditions $\left(F_{3,296}=5.38, p<0.001\right)$, with Bonferroni corrected multiple comparisons showing that the control condition felt significantly less hypocritical than any of the experimental conditions. However, these post-hoc tests did not show any significant difference between the three experimental conditions. Transgression scores for those in the hypocrisy condition were marginally significantly positively correlated with self-reported hypocrisy $(r=0.24, p=0.08)$.

\subsubsection{Dependent Variables}

The policy approach items were re-written to be more focused and reduced to three items to clearly illustrate different political strategies with minimal crossover. The items were:

- "There will be more control over businesses to produce and sell only sustainable, easily repairable and ethical products (e.g., cheaply produced clothes and single use plastics will be banned). Making these products unavailable is the best way to ensure we can reduce our material consumption.", representing 'National Governance and Regulation',

- "Business will be given more freedom to meet consumer demand. Products will become more environmentally-friendly if people buy more 'green' products and don't buy harmful or unsustainable products. If people don't want environmentally damaging products, they won't buy them. People can be trusted to make informed decisions about what they buy", representing 'Personal governance with deregulation of free markets'

- "There will be an increase in local community led projects where people can borrow tools and appliances from a 'library of things', instead of individually owning products we don't use all the time. There will be more space made available for allotments and community growing. People will work fewer days a week, allowing for more time to be spent with friends and family, and making or repairing their own products instead of buying new things.", representing 'Local and community governance with radical change'.

Once again, these were measured on a 7-item scale (rated 1-7, 'completely oppose' (1) to 'completely support' (7)).

Behavioural intention measures were kept largely the same as in Study 1 and mirrored the changes made to the transgressions, with the small amendments made to try and reduce 'don't know' responses. Participants were asked 'Think about the next month, and your intentions regarding the following actions. 'How often will you ... ?' in relation to the six items (rated 1-5, 'not at all' (1), 'once' (2), 'a few times' (3), 'often' (4), 'always' (5), and 'don't know' which was removed from analysis).

\subsection{Results}

\subsubsection{Policy Measure Support}

A MANOVA was conducted (using Pillai's trace), finding a significant effect of experimental manipulation on policy support $V=0.143, F_{9,291}=4.93, p<0.001$. Between-subject effects showed significant effects on national governance to regulate consumption $\left(F_{3,297}=14.03, p<0.001\right)$ and radical change at local governance level $\left(F_{3,297}=3.74, p=0.012\right)$. Deregulation was not significantly affected. Bonferroni corrected multiple comparisons showed a significant difference in support for regulation measures between control and all three experimental conditions $(p<0.001)$, but no significant difference between the three experimental conditions. Additionally, Bonferroni corrected multiple 
comparisons showed a significant difference in support for radical change measures between control and information-only condition $(p<0.01)$, but no significant difference between any other conditions (Figures 7-9).

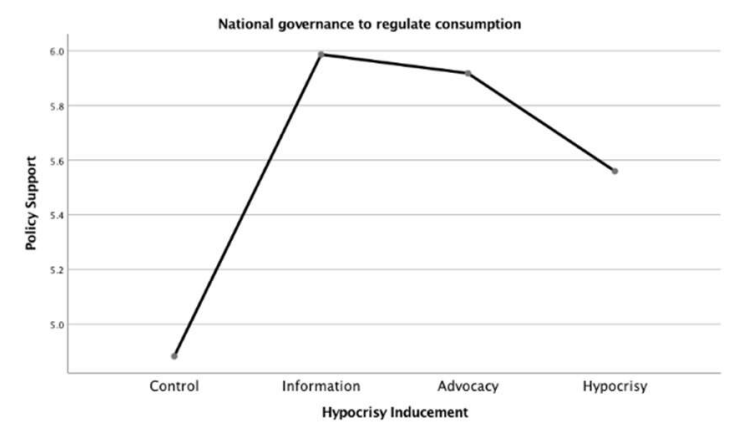

Figure 7. Policy support for national governance.

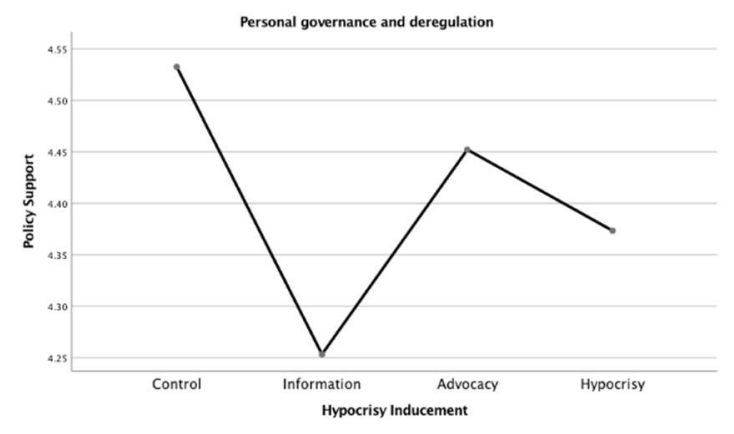

Figure 8. Policy support for personal governance.

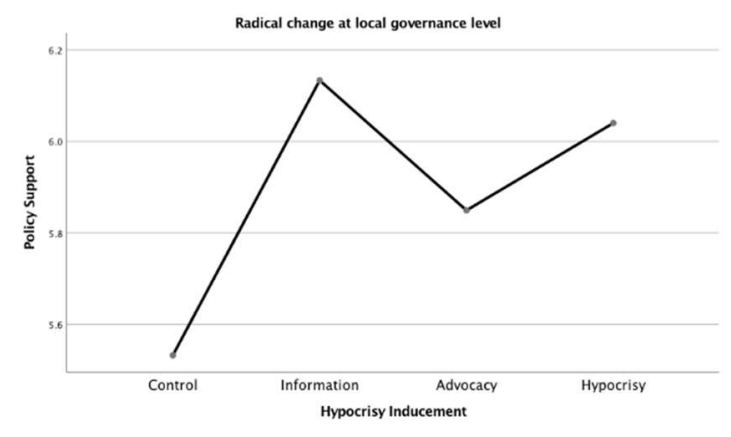

Figure 9. Policy support for community governance.

\subsubsection{Behavioural Intentions}

A MANOVA was conducted (using Pillai's trace), finding a significant effect of experimental manipulation on behavioural intentions $V=0.197, F_{18,282}=2.81, p<0.001$. Between-subject comparisons showed significant effects on reducing behavioural intentions of all of the items: Intention to use plastic $\left(F_{3,297}=8.13, p<0.001\right)$; Intention to buy unethically $\left(F_{3,297}=7.25, p<0.001\right)$; Intention to waste food $(F(3,297)=3.10, p<0.05)$; Intention to buy something you don't need $\left(F_{3,297}=9.90, p<0.001\right)$; Intention to buy new instead of repair $\left(F_{3,297}=9.91, p<0.001\right)$; Intention to buy expensive luxuries $\left(F_{3,297}=6.61, p<0.001\right)$. Bonferroni corrected multiple comparisons showed a significant difference in consumer intentions between control and hypocrisy groups across all items $(p<0.001)$, but no significant difference between the control, information only, and advocacy groups, with two exceptions. These exceptions showed that Bonferroni corrected multiple comparisons were significantly different in reducing behavioural intention to buy things you don't need (with significant differences between information-only and hypocrisy, both $p<0.001$, as well as the aforementioned control and hypocrisy 
conditions) and buy new instead of repair items (where all conditions were significantly different to hypocrisy, $p<0.01$ ) (Figures 10-15).

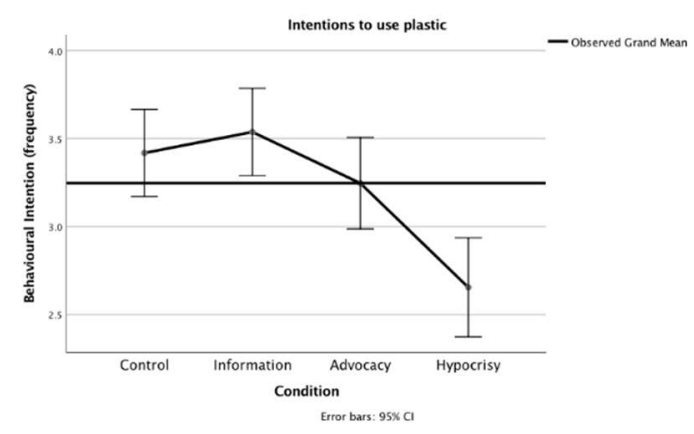

Figure 10. Intention to use single use plastic.

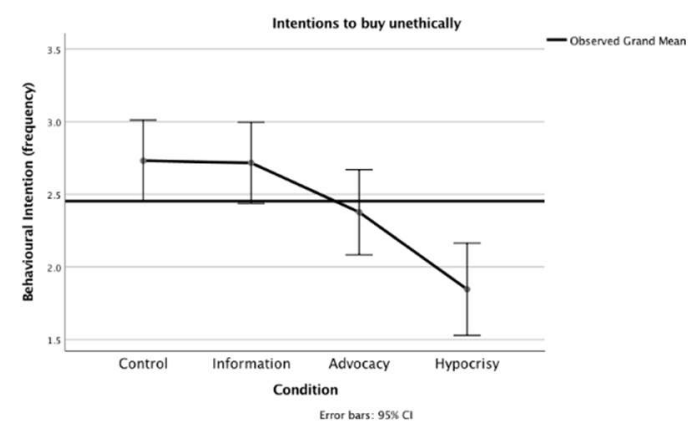

Figure 11. Intention to buy unethical products.

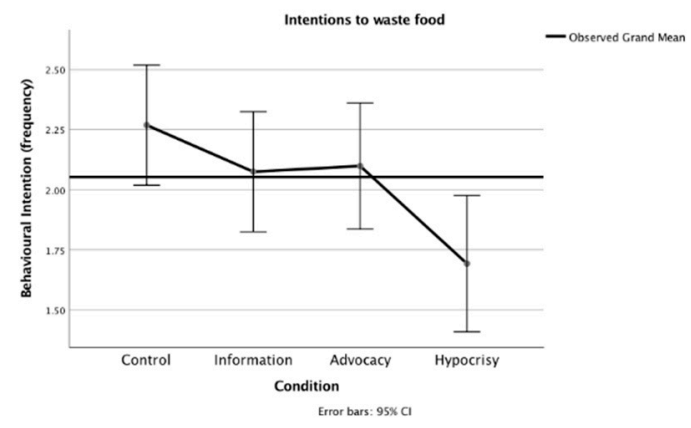

Figure 12. Intention to waste food.

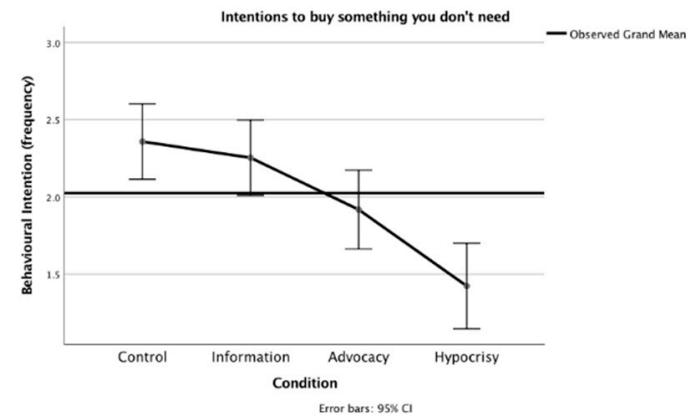

Figure 13. Intention to use single use plastic. 


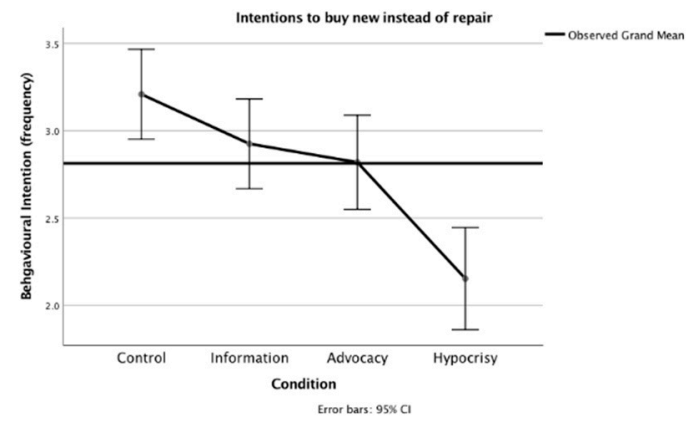

Figure 14. Intention to buy new instead of repair.

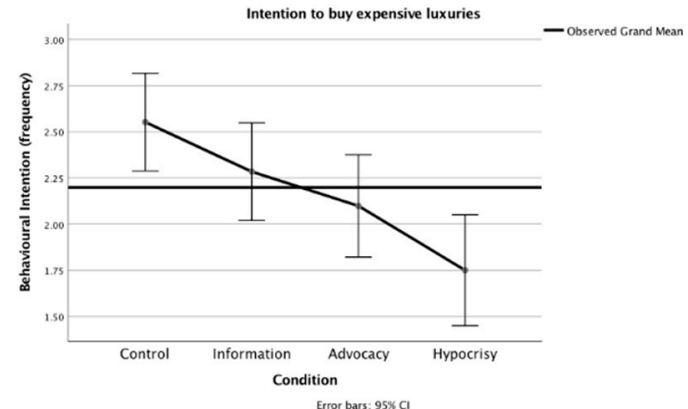

Figure 15. Intention to buy expensive luxuries.

\subsection{Discussion}

The hypotheses for Study 2 were adopted from Study 1 and sought observe the effect that was predicted in light of the literature reviewed originally, rather than to replicate any findings from Study 1. We cannot fully accept $\mathrm{H} 4$, as the only significant differences we found were in comparison to the pure control group. We can accept $\mathrm{H} 5$ as we found that the hypocrisy condition showed significantly lower intentions to engage in consumption behaviour.

Study 2 shows that the provision of information about the seriousness of climate change and the relevance of individual-level consumption behaviours can increase support for stronger regulation at a national governance level and for locally led community level governance for radical lifestyle changes. The addition of a control group allowed us to recognise the marked difference between those who were given the information statement, and those who were not. However, the experimental manipulation levels were not significantly different from each other with regards to support for public policy and governance. Self-reported measures of hypocrisy and cognitive dissonance show that the control group felt significantly less hypocritical than the other groups, so perhaps a mechanism of hypocrisy was already activated by the mere presentation of information.

Hypocrisy was significantly more effective at reducing behavioural intentions for consumption, with those participants who were rated their transgressions showing the lowest intentions for consumption behaviour in the future. We did not replicate the marginal rebound effect found in study 1; however, with such a clear pattern of significance across all of the items (and improved design), we can be more confident in the findings from Study 2. Making participants aware of their hypocrisy appears to have motivated them to ameliorate this discrepancy by intending to act in accordance with their recently signed advocacy statement.

\section{General Discussion}

Hypocrisy inducement yielded an interesting mix of effects upon policy acceptance. The introduction of a pure control group in Study 2 allowed us to demonstrate the effect of information provision upon support for more regulation at national governance level and radical change in local communities. It is possible that the provision of this information alone increased feelings of hypocrisy, as all conditions that were given the information self-reported higher hypocrisy. Further examination 
of how a process of information provision might provoke reflection and associated guilt might help to further understand this finding. Supporting stronger regulation on consumption could be seen to absolve the individual of responsibility, which is consistent with focus group research where we found that participants believed governments should do more to reduce consumption [23].

Hypocrisy may be best at influencing an intention to change behaviour. However, taken together with the findings of these two studies and the results regarding policy options and governance levels, we can suspect that hypocrisy reinforces a sense of the 'neo-liberal self' in people, resulting in higher support for deregulation and free-market solutions. So profound is the entrenched nature of neo-liberalism, the environmental movement itself has often focused on individual agency and decision-making responsibility [70-72]. Governments and activists alike have often sought to influence individual actions that are 'simple and painless' rather than attempting more ambitious change [73]. The findings in this current study show that inducing hypocrisy reproduces support for policy that places responsibility on individual decision making, which could be what is causing hypocrisy in the first place. This interesting paradox should be further explored in order to unpack hypocrisy and its self-perpetuating impact on policy and governance.

Interestingly, the most effective manipulations of hypocrisy upon behavioural intentions were for the more challenging lifestyle changes. Consuming ethically and repairing consumer items require some effort on behalf of the individual and yet they were most significantly increased by the intervention. This shows that hypocrisy may be a powerful tool for changing intentions for more difficult to change behaviours.

The dynamic social norms framing was not found to be effective in influencing low-consumption behavioural intentions in Study 1, which is most likely due to the dominance of consumption-based living. Therefore, it could be more useful to seek ways for social norms to be generated through policy and governance, rather than attempting to generate support for a policy through a descriptive social norm framing (which is misaligned with social reality). The implementation of public policy can contribute to the emergence of social norms and increase public support and acceptance, where this might have been lacking prior to launching. Nyborg et al. [74] explored how recycling was once unpopular; however, with the introduction of policy, regulation and infrastructure it has now become socially normalised and widespread. Similar effects could be explored in future research on social norms and low consumption.

A moderating effect of social norms on hypocrisy is noted for further investigation within a hypocrisy paradigm. Study 1 showed a 'boomerang effect' where advocating for a pledge after being primed with dynamic social norms framing increased intentions to consume less, but when hypocrisy was induced after pledge advocacy the intention to consume was higher. Study 2, which did not employ any social norms, had none of these rebound effects. The inducement of hypocrisy here only increased the intended effect of the manipulation in intentions to engage in low-consumption behaviours. Although this study removed social norms due to a lack of effect, the inconsistencies between findings in Studies 1 and 2 could be further explored and potentially explained by social norms interaction effects.

\section{Limitations and Future Research}

Due to recruitment methods the sample here was slightly skewed towards left-wing and lower-income groups. With an ever-changing political climate in the UK, we cannot be sure how representative this sample is to the UK population at the time of data collection in 2019. This single item measure of political orientation is fairly primitive and might not be easily understood, hence the complexities of political identity in the UK in 2019 cannot possibly be captured by it, and therefore we cannot make claims based on this measure in our research. Critically, the measure of political affiliation was balanced across conditions; as such any experimental findings were due to conditional differences not sample bias. However, it would be useful for future research to examine more closely how political identity (particularly right-wing) and/or income levels (particularly higher income) might 
affect policy support and behavioural intentions in this domain. Another sample-based concern is that the participants in study 2 were skewed towards females. Again, as this was not significantly different across groups, we can be confident of our research findings, but future research would be advised to redress this.

A possible limitation was that we chose to operationalize governance levels in terms of aggregate, but relatively crude, categories of policy which encompassed multiple elements; as such, we do not know whether there were particular aspects of the policies that respondents supported or opposed. This approach allows for a more holistic assessment (and arguably one that is more ecologically valid, as it captures more complexity and exposes trade-offs) of governance approaches across multiple scales, but at the expense of a fine-grained analysis of specific policy elements. Public responses to these policy elements could be examined in future work.

A further limitation of this study could be said to be that it looks only at behavioural intentions, rather than actual behaviour. However, research on hypocrisy has found a greater effect upon behaviour than attitudes, so this contributes towards understanding how hypocrisy might influence intentions to consume less. Future research would be well poised to explore the effect upon actual behaviour change in light of the findings here.

This paper details how hypocrisy can influence consumption-related behavioural intentions, providing a rationale for it to be explored as a mechanism in economic and moral decision making. This study did not collect data on the reflections of the participants, and as such we cannot infer how much agency participants felt they had in making their decision making. Seeing how hypocrisy might relate to other psychological traits should form part of a new research agenda in this area and could help further explore agency and ability to change. Measuring other variables such as, for example, self-efficacy and perceived behavioural control could help explain further how a sense of responsibility and inability to act manifests in those experiencing hypocrisy. These factors could be boundary conditions that moderate or mediate the effectiveness of hypocrisy inducement upon behaviour change.

Author Contributions: The research in this article was carried our by D.T. as part of a PhD research project. The project was supervised by L.W. and C.D., therefore they had significant input into the conception and design. The article was written by D.T. with drafting suggestions and edits from L.W. and C.D. All authors have read and agreed to the published version of the manuscript.

Funding: This research received no external funding

Conflicts of Interest: The authors declare no conflict of interest

\section{Appendix A Information Statement}

Please read the following information carefully. You will be asked questions on some of the details to test your knowledge at a later stage.

The world is experiencing climate change, and changes need to be made in order to avoid levels of global warming that would threaten the existence of human societies and the living planet. The Paris Agreement has set targets to achieve the positive change needed to avert crisis. In order to meet these goals, the models and future scenario pathways show that new technology and increased energy efficiency will not be enough to help change this. The target is to limit global warming to $1.5 \mathrm{c}$, and this would require 'Aggressive emissions reductions', however, if we continue as we are now ('Business as usual') we are more likely to reach 3-5c, which scientists report to be catastrophic. We will need to reduce our consumption in order to help tackle this problem effectively as part of an 'Aggressive emissions reduction' strategy.

At the moment our consumption levels exceed the sustainable amount of resources the earth can provide. Research has shown that if everyone lived like we do in the U.K. we would need 4 planet Earths to use the resources sustainably. We only have one planet, with limited resources, therefore it is not feasible to maintain this level of consumption; to keep burning fossil fuels, or digging up natural resources and materials, or using more land for agriculture. 


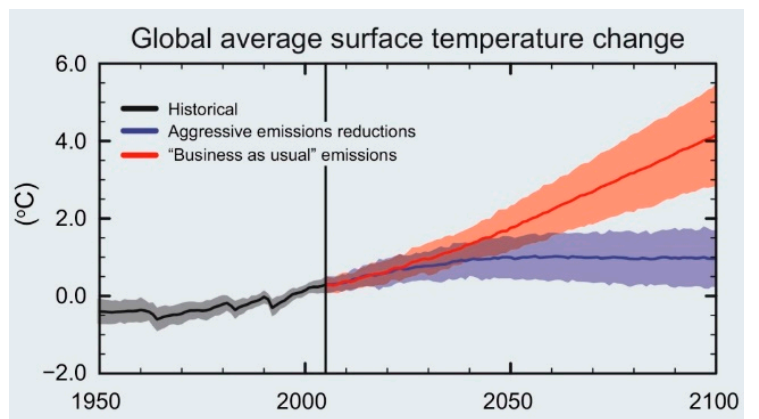

Figure A1. Projections of global average surface change.

We now use 8 times as many resources compared to the start of the 20th Century, and reducing this will be key to avoiding catastrophic climate change. Research has shown that we need to reduce our carbon footprint associated with clothing, packaging, electronics, appliances, vehicles, and buildings.

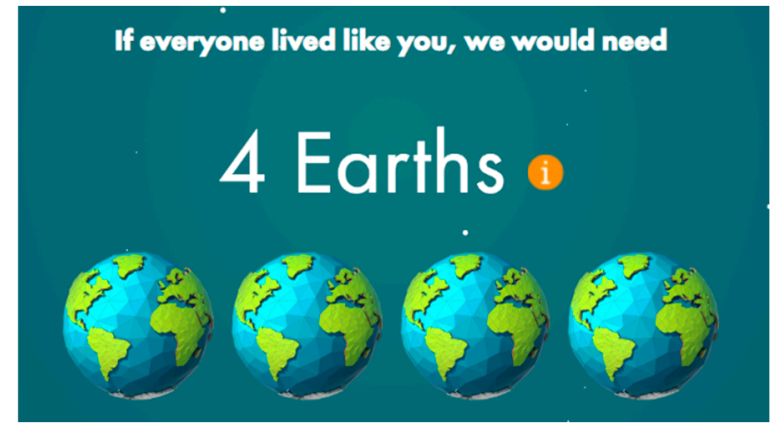

Figure A2. Consumption footprint calculator.

High consumption lifestyles have been linked to a variety of problems such as depression, anxiety, and generally a lower sense of life-satisfaction or individual well-being. Therefore, not only is it better for society and the planet to consume less, it is better for our own state of health.

\section{Appendix B Exclusion Criteria}

Any participants who failed both knowledge check questions, and those who failed to follow the required steps for effective experimental manipulation, were removed from the analysis (see below for details on knowledge checks). The final number of participants after these exclusion criteria were applied was 259; therefore, this is the number reported in the main body of the text.

\section{Appendix B.1 Knowledge Check}

All participants were asked two multiple choice questions regarding the information statement they had been presented with: "How many planet Earths would we need if everyone in the world consumed like the average UK citizen currently does?" (' 1 ', ' 4 ', or ' 8 ', with ' 4 ' being correct), and "Since the start of the 20th Century we have increased our use of resources by ... " ('two times', 'eight times' and 'twelve times', with 'eight times' being correct). Those participants in the social norms condition were asked two further multiple choice questions related to the extra information they received: "How many people agreed that the UK has a problem with over-consumption?" ('15\%', ' $58 \%$ ', or ' $72 \%$ ', with ' $72 \%$ ' being correct), and "Of those people, how many were starting to reduce their consumption?" ('10\%', ' $45 \%$ ' or ' $62 \%$ ', with ' $45 \%$ ' being correct). These were designed to test the knowledge of information-only control and knowledge of the social norms condition and to check they had given an acceptable level of attention. 


\section{Appendix B.2 Social Norms Manipulation Check}

The manipulation checks were focused on establishing any significant differences (or lack of) in the perceived accuracy of the statistics between the conditions. Social norm manipulations sought non-significant difference between the two groups in response to the question "Think about the information you were given about consumption and climate change and the beginning of this survey. To what extent do you agree that ... ?" across three items: "The information was overblown or exaggerated', 'The statistics were trying to manipulate my attitudes', and 'The statistics were accurate' (on a 1-7 response scale: Completely disagree (1), strongly disagree (2), slightly disagree (3), neither agree nor disagree (4), slightly agree (5), strongly agree (6), completely agree (7)). The social norms conditions were presented with statistics that were not true, therefore if the manipulation was successful, their responses to these questions would not be significantly different to those who only saw the factual information statement in the control condition.

Table A1. Social norm manipulation check.

\begin{tabular}{|c|c|c|c|c|c|c|c|c|c|}
\hline \multirow[t]{2}{*}{ Condition } & \multicolumn{3}{|c|}{$\begin{array}{c}\text { Over-Exaggerated Statistic } \\
\text { (Agree, \%) }\end{array}$} & \multicolumn{3}{|c|}{$\begin{array}{c}\text { Manipulating Attitudes } \\
\text { (Agree, \%) }\end{array}$} & \multicolumn{3}{|c|}{$\begin{array}{l}\text { Accurate Statistics } \\
\text { (Disagree, \%) }\end{array}$} \\
\hline & Slightly & Strongly & Completely & Slightly & Strongly & Completely & Slightly & Strongly & Completely \\
\hline $\begin{array}{l}\text { Information } \\
\text { Only }(n, 137)\end{array}$ & 13.1 & 2.9 & 0.0 & 33.6 & 15.3 & 5.1 & 6.6 & 0.0 & 0.0 \\
\hline $\begin{array}{l}\text { Social Norms } \\
\quad(n, 122)\end{array}$ & 14.0 & 0.0 & 0.0 & 35.2 & 9.0 & 4.1 & 5.7 & 0.8 & 0.0 \\
\hline
\end{tabular}

An independent $\mathrm{t}$-test was used to compare the group means of those who were exposed to the dynamic social norm framing and those who were not. The t-tests showed non-significance for over-exaggerated statistics $(\mathrm{t}(257)=-0.88, p=0.38)$, manipulating attitudes $(\mathrm{t}(257)=1.03, p=0.30)$, and accurate statistics $(\mathrm{t}(257)=0.946, p=0.35)$. This supports the notion that there was no difference between how each group perceived the accuracy of the information, whether they were exposed to only facts, or both facts and falsified social norms.

\section{References}

1. Cook, J.; Oreskes, N.; Doran, P.T.; Anderegg, W.R.; Verheggen, B.; Maibach, E.W.; Nuccitelli, D. Consensus on consensus: A synthesis of consensus estimates on human-caused global warming. Environ. Res. Lett. 2016, 11, 048002. [CrossRef]

2. Intergovernmental Panel on Climate Change. Global Warming of $1.5^{\circ} \mathrm{C}$ : An IPCC Special Report on the Impacts of Global Warming of $1.5^{\circ} \mathrm{C}$ Above Pre-industrial Levels and Related Global Greenhouse Gas Emission Pathways, in the Context of Strengthening the Global Response to the Threat of Climate Change, Sustainable Development, and Efforts to Eradicate Poverty; Intergovernmental Panel on Climate Change: Geneva, Switzerland, 2018.

3. Xu, Y.; Ramanathan, V. Well below $2 \mathrm{C}$ : Mitigation strategies for avoiding dangerous to catastrophic climate changes. Proc. Natl. Acad. Sci. USA 2017, 114, 10315-10323. [CrossRef] [PubMed]

4. Rogelj, J.; Popp, A.; Calvin, K.V.; Luderer, G.; Emmerling, J.; Gernaat, D.; Krey, V. Scenarios towards limiting global mean temperature increase below 1.5 C. Nat. Clim. Change 2018, 8, 325. [CrossRef]

5. Cherry, C.; Scott, K.; Barrett, J.; Pidgeon, N. Public acceptance of resource-efficiency strategies to mitigate climate change. Nat. Clim. Change 2018, 8, 1007. [CrossRef]

6. Allwood, J.M.; Ashby, M.F.; Gutowski, T.G.; Worrell, E. Material efficiency: Providing material services with less material production. Philos. Trans. Royal Society. 2013, 371. [CrossRef] [PubMed]

7. Tukker, A.; Jansen, B. Environmental impacts of products: A detailed review of studies. J. Ind. Ecol. 2006, 10, 159-182. [CrossRef]

8. Young, S.B. Responsible sourcing of metals: Certification approaches for conflict minerals and conflict-free metals. Int. J. Life Cycle Assess. 2018, 23, 1429-1447. [CrossRef]

9. Vrijheid, M. Health effects of residence near hazardous waste landfill sites: A review of epidemiologic literature. Environ. Health Perspect. 2000, 108, 101-112. 
10. Department for Environment Food \& Rural Affairs UK Statistics on Waste. Available online: https://assets.publishing.service.gov.uk/government/uploads/system/uploads/attachment_data/file/784263/UK_ Statistics_on_Waste_statistical_notice_March_2019_rev_FINAL.pdf (accessed on 5 February 2020).

11. Biesbroek, G.R.; Swart, R.J.; Carter, T.R.; Cowan, C.; Henrichs, T.; Mela, H.; Rey, D. Europe adapts to climate change: Comparing national adaptation strategies. Glob. Environ. Change 2010, 20, 440-450. [CrossRef]

12. Bodansky, D. The Paris climate change agreement: A new hope? Am. J. Int. Law 2016, 110, $288-319$. [CrossRef]

13. Falkner, R. The Paris Agreement and the new logic of international climate politics. Int. Aff. 2016, 92, 1107-1125. [CrossRef]

14. Russel, D.; Beck, S.; Campos, I.; Capriolo, A.; Castellari, S.; Gebhardt, O.; Hildén, M.; Jensen, A.; Karali, E.; Mäkinen, K.; et al. Analyzing the Policy Framework for Climate Change Adaptation. In Adapting the Future for Climate Change in Europe; Sanderson, H., Hildén, M., Russel, D.J., Penha-Lopes, G., Capriolo, A., Eds.; Elsevier: Amsterdam, the Netherlands, 2018.

15. Jordan, A.; Huitema, D.; Hildén, M.; van Asselt, H.; Rayner, T.; Schoenefeld, J.; Tosun, J.; Forster, J.; Boassson, E.L. Emergence of polycentric climate governance and its future prospects. Nat. Clim. Change 2015, 5, 977-982. [CrossRef]

16. Jordan, A.; Huitema, D.; Van Asselt, H.; Forster, J. Governing Climate Change: Polycentricity in Action? Cambridge University Press: Cambridge, UK, 2018; pp. 303-319.

17. Cole, D.H. Advantages of a polycentric approach to climate change policy. Nat. Clim. Change 2015, 5, 114-118. [CrossRef]

18. Keskitalo, E.C.H.; Juhola, S.; Baron, N.; Fyhn, H.; Klein, J. Implementing local climate change adaptation and mitigation actions: The role of various policy instruments in a multi-level governance context. Climate 2016, 4, 7. [CrossRef]

19. Campos, I.; Ng, K.; Penha-Lopes, G.; Pedersen, A.B.; Capriolo, A.; Olazabal, M.; Meyer, V.; Gebhardt, O.; Weiland, S.; Nielsen, Ø.H.; et al. The diversity of Adaptation in a Multi-Level Governance Setting. In Adapting the Future for Climate Change in Europe; Sanderson, H., Hildén, M., Russel, D.J., Penha-Lopes, G., Capriolo, A., Eds.; Elsevier: Amsterdam, the Netherlands, 2018.

20. Gintis, H. Consumer behavior and the concept of sovereignty: Explanations of social decay. Am. Econ. Rev. 1972, 62, 267-278.

21. Lerner, A.P. The economics and politics of consumer sovereignty. Am. Econ. Rev. 1972, 62, 258-266.

22. Sanne, C. Willing consumers-or locked-in? Policies for a sustainable consumption. Ecol. Econ. 2002, 42, 273-287. [CrossRef]

23. Thorman, D. Public Acceptability of Low-Consumption Futures; Tyndall Assembly 2018; University of East Anglia: Norwich, UK, 2018.

24. Perrucci, R.; Perrucci, C.C. The good society: Core social values, social norms, and public policy. Sociol. Forum 2014, 29, 245-258. [CrossRef]

25. Folke, C.; Carpenter, S.R.; Walker, B.; Scheffer, M.; Chapin, T.; Rockström, J. Resilience thinking: Integrating resilience, adaptability and transformability. Ecol. Soc. 2020, 15, 20. Available online: www.jstor.org/stable/ 26268226 (accessed on 7 February 2020). [CrossRef]

26. Willis, R. Building the Political Mandate for Climate Action; Green Alliance: London, UK, 2018.

27. Fiorino, D.J. Citizen participation and environmental risk: A survey of institutional mechanisms. Sci. Technol. Hum. Values 1990, 15, 226-243. [CrossRef]

28. Farrow, K.; Grolleau, G.; Ibanez, L. Social norms and pro-environmental behavior: A review of the evidence. Ecol. Econ. 2017, 140, 1-13. [CrossRef]

29. Poškus, M.S. Using social norms to encourage sustainable behaviour: A meta-analysis. Psychology 2016, 53, $44-58$.

30. Gamma, K.; Mai, R.; Loock, M. The double-edged sword of ethical nudges: Does inducing hypocrisy help or hinder the adoption of pro-environmental behaviors? J. Bus. Ethics 2018, 1-23. [CrossRef]

31. Huddart Kennedy, E.; Krahn, H.; Krogman, N.T. Are we counting what counts? A closer look at environmental concern, pro-environmental behaviour, and carbon footprint. Local Environ. 2015, 20, 220-236. [CrossRef]

32. Festinger, L. A Theory of Cognitive Dissonance; Stanford University Press: Stanford, CA, USA, 1957.

33. Stone, J.; Wiegand, A.W.; Cooper, J.; Aronson, E. When exemplification fails: Hypocrisy and the motive for self-integrity. J. Personal. Soc. Psychol. 1997, 72, 54. [CrossRef] 
34. Elliot, A.J.; Devine, P.G. On the motivational nature of cognitive dissonance: Dissonance as psychological discomfort. J. Personal. Soc. Psychol. 1994, 67, 382. [CrossRef]

35. Foad, C. Social context mismatch theory (Doctoral dissertation, Cardiff University). Available online: http://orca.cf.ac.uk/id/eprint/84359 (accessed on 30 March 2016).

36. Aronson, E.; Fried, C.; Stone, J. Overcoming denial and increasing the intention to use condoms through the induction of hypocrisy. Am. J. Publ. Health 1991, 81, 1636-1638. [CrossRef]

37. Dickerson, C.A.; Thibodeau, R.; Aronson, E.; Miller, D. Using cognitive dissonance to encourage water conservation 1. J. Appl. Soc. Psychol. 1992, 22, 841-854. [CrossRef]

38. Fointiat, V. "I know what I have to do, but ... " When hypocrisy leads to behavioral change. Soc. Behav. Personal. Int. J. 2004, 32, 741-746. [CrossRef]

39. Morrongiello, B.A.; Mark, L. "Practice what you preach": Induced hypocrisy as an intervention strategy to reduce children's intentions to risk take on playgrounds. J. Pediatr. Psychol. 2008, 33, 1117-1128. [CrossRef]

40. Rubens, L.; Gosling, P.; Bonaiuto, M.; Brisbois, X.; Moch, A. Being a hypocrite or committed while I am shopping? A comparison of the impact of two interventions on environmentally friendly behavior. Environ. Behav. 2015, 47, 3-16. [CrossRef]

41. Peterson, A.A.; Haynes, G.A.; Olson, J.M. Self-esteem differences in the effects of hypocrisy induction on behavioral intentions in the health domain. J. Personal. 2008, 76, 305-322. [CrossRef] [PubMed]

42. Sénémeaud, C.; Mange, J.; Fointiat, V.; Somat, A. Being hypocritical disturbs some people more than others: How individual differences in preference for consistency moderate the behavioral effects of the induced-hypocrisy paradigm. Soc. Influ. 2014, 9, 133-148. [CrossRef]

43. Stone, J.; Fernandez, N.C. When thinking about less failure causes more dissonance: The effect of elaboration and recall on behavior change following hypocrisy. Soc. Influ. 2011, 6, 199-211. [CrossRef]

44. Eitel, P.; Friend, R. Reducing denial and sexual risk behaviors in college students: A comparison of a cognitive and a motivational approach. Ann. behav. Med. 1999, 21, 12-19. [CrossRef] [PubMed]

45. Hammons, M. Examining the hypocrisy paradigm as an intervention for modifying high-risk alcohol use behaviors among college students. Electron. Theses Diss 2010. Available online: http://purl.fcla.edu/fcla/etd/ CFE0003237 (accessed on 4 February 2020).

46. Priolo, D.; Milhabet, I.; Codou, O.; Fointiat, V.; Lebarbenchon, E.; Gabarrot, F. Encouraging ecological behaviour through induced hypocrisy and inconsistency. J. Environ. Psychol. 2016, 47, 166-180. [CrossRef]

47. Simmons, V.N.; Webb, M.S.; Brandon, T.H. College-student smoking: An initial test of an experiential dissonance-enhancing intervention. Addict. Behav. 2004, 29, 1129-1136. [CrossRef]

48. Stone, J.; Aronson, E.; Crain, A.L.; Winslow, M.P.; Fried, C.B. Inducing hypocrisy as a means of encouraging young adults to use condoms. Personal. Soc. Psychol. Bull. 1994, 20, 116-128. [CrossRef]

49. Stone, J.; Fernandez, N.C. To practice what we preach: The use of hypocrisy and cognitive dissonance to motivate behavior change. Soc. Personal. Psychol. Compass 2008, 2, 1024-1051. [CrossRef]

50. McConnell, A.R.; Brown, C.M. Dissonance averted: Self-concept organization moderates the effect of hypocrisy on attitude change. J. Exp. Soc. Psychol. 2010, 46, 361-366. [CrossRef]

51. Stone, J.; Focella, E. Hypocrisy, dissonance and the self-regulation processes that improve health. Self Identity 2011, 10, 295-303. [CrossRef]

52. Aronson, E. Dissonance, hypocrisy, and the self-concept. Read. Soc. Anim. 1999, 103-126. [CrossRef]

53. Cialdini, R.B.; Kallgren, C.A.; Reno, R.R. A focus theory of normative conduct: A theoretical refinement and reevaluation of the role of norms in human behavior. Adv. Exp. Soc. Psychol. 1991, 24, 201-234.

54. Dernbach, J.C.; Brown, D.A. The ethical responsibility to reduce energy consumption. Hofstra L. Rev. 2008, 37, 985. [CrossRef]

55. Lede, E. Applying Social Identity Insights to Encourage Climate Resilient Water Behaviour. Ph.D. Thesis, University of East Anglia, Norwich, UK, 2018.

56. Sparkman, G.; Walton, G.M. Dynamic norms promote sustainable behavior, even if it is counternormative. Psychol. Sci. 2017, 28, 1663-1674. [CrossRef]

57. Culiberg, B.; Elgaaied-Gambier, L. Going green to fit in-understanding the impact of social norms on pro-environmental behaviour, a cross-cultural approach. Int. J. Consum. Stud. 2016, 40, 179-185. [CrossRef]

58. Stok, F.M.; De Ridder, D.T.; De Vet, E.; De Wit, J.B. Don't tell me what I should do, but what others do: The influence of descriptive and injunctive peer norms on fruit consumption in adolescents. Br. J. Health Psychol. 2014, 19, 52-64. [CrossRef] 
59. Onwezen, M.C.; Bartels, J.; Antonides, G. Environmentally friendly consumer choices: Cultural differences in the self-regulatory function of anticipated pride and guilt. J. Environ. Psychol. 2014, 40, 239-248. [CrossRef]

60. Van Dam, Y.K.; van Trijp, J.C.M. Interventions to encourage sustainable consumption. Appl. Stud. Agribus. Commer. 2016, 10, 51-58. [CrossRef]

61. Kinzig, A.P.; Ehrlich, P.R.; Alston, L.J.; Arrow, K.; Barrett, S.; Buchman, T.G.; Ostrom, E. Social norms and global environmental challenges: The complex interaction of behaviors, values, and policy. Bioscience 2013, 63, 164-175. [CrossRef] [PubMed]

62. Luís, S.; Palma-Oliveira, J. Public policy and social norms: The case of a nationwide smoking ban among college students. Psychol. Publ. Policy Law 2016, 22, 22. [CrossRef]

63. Richter, I.; Thøgersen, J.; Klöckner, C. A social norms intervention going wrong: Boomerang effects from descriptive norms information. Sustainability 2018, 10, 2848. [CrossRef]

64. Cialdini, R.B.; Demaine, L.J.; Sagarin, B.J.; Barrett, D.W.; Rhoads, K.; Winter, P.L. Managing social norms for persuasive impact. Soc. Influ. 2006, 1, 3-15. [CrossRef]

65. Schultz, P.W.; Nolan, J.M.; Cialdini, R.B.; Goldstein, N.J.; Griskevicius, V. The constructive, destructive, and reconstructive power of social norms. Psychol. Sci. 2007, 18, 429-434. [CrossRef] [PubMed]

66. Household Final Consumption Expenditure: Household Goods \& Services; Office of National Statistics: London, UK, 2019.

67. Liégeois, A.; Yserbyt, V.; Corneille, O. I'm dirty as anyone else... So what? When attempts at inducing hypocrisy backfire. In Proceedings of the Annual Meeting of the Belgian Association for Psychological Sciences (BAPS), Ghent University, Ghent, Belgium, 5 May 2005.

68. Vinski, E.J.; Tryon, G.S. Study of a cognitive dissonance intervention to address high school students' cheating attitudes and behaviors. Eth. Behav. 2009, 19, 218-226. [CrossRef]

69. Fried, C.B. Hypocrisy and identification with transgressions: A case of undetected dissonance. Basic Appl. Soc. Psychol. 1998, 20, 144-154. [CrossRef]

70. Hursh, D.W.; Henderson, J.A. Contesting global neoliberalism and creating alternative futures. Discourse Stud. Cult. Pol. Educ. 2011, 32, 171-185. [CrossRef]

71. McCarthy, J.; Prudham, S. Neoliberal nature and the nature of neoliberalism. Geoforum 2004, 35, $275-283$. [CrossRef]

72. McDonald, M.; Gough, B.; Wearing, S.; Deville, A. Social psychology, consumer culture and neoliberal political economy. J. Theory Soc. Behav. 2017, 47, 363-379. [CrossRef]

73. Thøgersen, J.; Crompton, T. Simple and painless? The limitations of spillover in environmental campaigning. J. Consum. Pol. 2009, 32, 141-163. [CrossRef]

74. Nyborg, K.; Anderies, J.M.; Dannenberg, A.; Lindahl, T.; Schill, C.; Schlüter, M.; Chapin, F.S. Social norms as solutions. Science 2016, 354, 42-43. [CrossRef] [PubMed]

(C) 2020 by the authors. Licensee MDPI, Basel, Switzerland. This article is an open access article distributed under the terms and conditions of the Creative Commons Attribution (CC BY) license (http://creativecommons.org/licenses/by/4.0/). 